\title{
Review: Breast cancer and etiology
}

\author{
Trivikram M Deshpande ${ }^{1}$, AK Pandey ${ }^{2 *}$ and SK Shyama ${ }^{1}$ \\ ${ }^{1}$ Department of Zoology, Goa University, Goa 403206, India \\ ${ }^{2}$ Department of Radiotherapy, Goa Medical College, Goa 403202, India
}

\section{Introduction}

'Cancer' in general, is an 'uncontrolled growth and division of cells'. It may genetically defined as a progressive series of genetic events that occur in a single clone of cells because of alterations in a limited number of specific genes viz. proto-oncogenes and tumor suppressor genes [1]. 'Breast cancer' is a malignant tumor that has developed from cells of the breast. It also implies carcinoma arising I the ductal and glandular structures of the breast [2].

\section{History of breast cancer}

The oldest record of breast cancer dates back to 1600 BC. A 468 meters long papyrus describing 48 surgical cases included at least 8 breast diseases and among these one was almost certainly breast tumor. Edwin Smith discovered this papyrus (Teba 1862), which is believed to be written by Imhotep who was proclaimed as a god in an old Egypt. This document on papyrus is the oldest known medical record. It is supposed that the papyrus was in fact a transcript made in $1600 \mathrm{BC}$, the original papyrus was much older from about $3000 \mathrm{BC}$ [3].

Also described in the treatment of these tumors or ulcers of the breast was the use of cauterization, with a tool called the 'fire drill.'The author conluded that there was no successful treatment for breast cancer.

A well-known patient from the end of the $6^{\text {th }}$ century BC, the queen of Atos, Kiros's daughter and Danius's wife supposedly had breast cancer. Herodot (a Greek historian) wrote, "she ha swelling of the breast (phyma) which broke and started to enlarge." However, she was completely cured without mutilation of the breast by the Persian doctor Democedes from Kroton. Hence, it is now believed that the queen did not have a malignant tumor but rather mastitis. In fact, Herodot who was usually very precise in his technical writing, in this case used the ambiguous word phyma which can either mean abscess or neoplasm. Herodot described Alase's (daughter of Cyrusa) case (535 $\mathrm{BC}$ ). She found a nodule in her breast but she concealed it until it broke through the skin like an open wound. Then her father called a doctor who successfully took out the tumor [3].

Celzo realized the value of surgery in the early stages of the breast tumor and said that only small tumors could be removed while larger tumors were only irritated by surgical intervention. Hippocrates (460 AD) distinguished between benign and malignant tumors. $\mathrm{He}$ considered breast cancer incurable. According to the doctrines of the Greek physician Galen (130-200) AD, melancholia was the chief factor in the development of breast cancer. Special diet and exorcism were the recommended treatments [3].

Santa Agatha is the women's patroness for breast cancer. According to the legend, she was an extremely beautiful girl from rich and respected family. She lived in Catania Sicily during the rule of the
Roman emperor Decia (200-251 AD). Decia sent his regent (governor) Kvintianto Sicily to exterminate the Christians. There he heard about the young and beautiful Agatha and he ordered for her to be brought for him. Agate, who was a Christian woman, declined him due to her religion. Therefore, Kvintian decided to throw her into prison. Then he sent Afrodisia, who was infamous for prostituting even her own daughters. For thirty days she unsuccessfully tried to convince Agatha to become Kvintian's. Exasperated, he ordered Agatha to be tortured. Her arms and legs were stretched by ancient devices then with glowing pincers one breast was amputated. Then Agatha asked "aren't you ashamed to cut off what your mother used to feed you with?" She was also forced to walk barefoot on hot coals. But then a huge earthquake caused one wall to fall into the court, which resulted her death. Agatha was sainted, the woman martyr and the patroness of breast diseases. Her sacrifice is remembered on February the $5^{\text {th }}[3]$.

Leonidus from Alexandra described breast cancer surgery for the first time in the first century after Christ. The procedure included removal of the cancer and some undiseased tissue and skin. To stop bleeding he used cauterization. Cutting and cauterization was performed until the whole tumor and the breast was removed and the injured surface became covered with a c crust.

An English physician, Thommas Willis (1621-1675), used almost the same definition of tumor with respect to neoplasia as it is used today. According to him, tumor is the 'disturbance of growing primary characterized cells with uncontrolled, non-purposefully dividing cells [3].”

During the Renaiscence, Andreas Vesalius (a Flemish anatomist who questioned the medical doctrines of Arisotle and Galen and whose "DeHumanicroporisfabrica" formed the basis from which modern research was developed), recommended mastectomy as ell as ligatures (sutures) to control the bleeding, rather than cautery. Recognition that breast cancer could spread to the regional auxillary nodes (lymph nodes under the underarm) was irst recognized by the physician LeDran (1685-1770). LeDran was likely the first to associate poor prognosis with the spread of breast cancer to the lymph nodes [3].

The first epidemiological data of breast cancer came from the Middlesex Hospital in London (1791-1805), where the first breast cancer cases were registered, 250 of the patients refused treatment. Although the study of anatomy improved in the $18^{\text {th }}$ century, the outcome of breast surgery did not due to infection, lack of good anesthesia and the use of complete radical mastectomy. A new era of

Correspondence to: Dr. Trivikram M. Deshpande, Department of Zoology, Goa University, India, E-mail: tridesh@yahoo.com; tridesh@gmail.com

Received: November 04, 2017; Accepted: November 23, 2017; Published: November 27, 2017 
surgery and medicine began with the discovery of $\mathrm{NO}$ as an anesthetic in 1846, antiseptic technique in 1867 and microscopical histological analysis.

Two physicians, Halstead and Meyer, brought light to the illfortuned women diagnosed with the breast cancer. In 1894 each independently announced their surgical procedures and results for treatment of breast cancer. They described, for that period of time, superior local control of disease by en bloc radical mastectomy which included total removal of affected breast, total ipsilateral axillary lymph node dissection in levels I-III, resection of pectoral major and minor muscles and rotine resection of thoracodorsal neurovascular network including the long thoracic nerve. Halstead's opinion was based on the study of well known German cellular pathologist Rudolf Virchow, who considers cancer local disease and the lymph nodes were the natural barrier to the dissemination of cancer cells. Based on this hypothesis, complete cure can only be achieved by the local removal of tumor along with adjacent healthy tissue. Halstead focused on treating the patients with high stage of the disease but he noticed the breast cancer in earlier stages as well. He reported the removal of an 'early' breast tumor $8 \mathrm{x}$ $7 \mathrm{~cm}$ in size. A ten years survival rate of $34 \%$ was realized which at that time was clearly superior to other efforts. Radical mastectomy according to Halstead brought a new era and approach to breast cancer treatment [3].

Wilhelm Conrad Rontgen (1845-1923) discovered X rays in 1895 and one year after Henry Becquerel uranium radioactivity. Pierre and Marie Curie isolated radium from uranium. Several attempts and failures occurred until 1912 W. Sampson Handley said: “The principle of using X-ray for treatment of breast cancer is prophylactic against postoperative relapse. Even in late stages of breast cancer $\mathrm{X}$ rays are an effective way of palliating the pain." During the mid 1900's X ray diagnosis of breast improved so dramatically that detection of nonpalpable tumor in the breast was enabled. This allowed new surgical operations such as lumpectomy, quadrantectomy and segmentectomy to be used [3].

From1896, when Beatson published that the surgical castration (bilateral oopherectomy) of two patients resulted in tumor regression, hormonal therapy of breast cancer has progressed through several stages but correlation between hormones and tumor growth was not proven until hormonal receptors were discovered on breast cancer cells. In 1955, Engell published proof of hematogenous dissemination of malignant cells. This research pushed efforts for systemic chemotherapeutic agents and immunotherapeutic agents for the treatment of metastatic breast cancer [3].

"Sisters of Mercy Hospital" in Zagreb, established in 1845 by the bishop Haulik in the monastry of St. Vinko, had 12 beds only for women and some of them were treated for breast cancer. The first hospital surgeon was Theodor Wicherhauser for whom Cackovic wrote, "he does not perform large operations even in cases of obvious carcinoma, he rather removes the breast containing cancer along with the axillary lymph nodes" [3].

\section{Classification of breast cancer}

Breast cancer is a heterogenous disease in terms of clinical course, gross and microscopic pathology and imaging characteristics. There are several histological classifications and the widely used one among them is the WHO classification (Table 1) and is as follows:

Table 1: WHO classification

\section{Noninvasive}

a. Intraductal

b. Lobular carcinoma in situ

Table 1. Hereditary cancers and inherited disease syndromes associated with a high incidence of cancer (short list).

\begin{tabular}{|c|c|c|}
\hline Disease/Syndrome & Associated Neoplasm & Inheritance \\
\hline Breast / Ovarian Cancer Syndrome & Early onset breast cancer/ovarian cancer & $\mathrm{D}$ \\
\hline $\begin{array}{l}\text { Chromosomal Instability } \\
\text { Syndromes: } \\
\text { Bloom's syndrome } \\
\text { Fanconi's anemia }\end{array}$ & $\begin{array}{l}\text { Leukemia, intestinal cancer } \\
\text { Leukemia, squamous carcinoma }\end{array}$ & $\begin{array}{l}\mathrm{R} \\
\mathrm{R}\end{array}$ \\
\hline $\begin{array}{l}\text { Hereditary Skin Diseases: } \\
\text { Xeroderma pigmentosa }\end{array}$ & Skin cancers & $\mathrm{R}$ \\
\hline $\begin{array}{l}\text { Endocrine system: } \\
\text { Multiple endocrine neoplasia } \\
\text { Zollinger-Ellison syndrome }\end{array}$ & $\begin{array}{l}\text { Adenomas of endocrine glands } \\
\text { Pancreatic and duodenal gastrinomas }\end{array}$ & $\begin{array}{l}\mathrm{D} \\
\mathrm{D}\end{array}$ \\
\hline $\begin{array}{l}\text { Nervous System: } \\
\text { Retinoblastoma } \\
\text { Neuroblastoma } \\
\text { Neurofibromatosis } \\
\text { (von Recklinghausen's) }\end{array}$ & $\begin{array}{l}\text { Retinoblastoma bilateral } \\
\text { Pheochromocytoma } \\
\text { Fibrosarcoma, meningioma }\end{array}$ & $\begin{array}{l}\mathrm{D} \\
\mathrm{R} \\
\mathrm{D}\end{array}$ \\
\hline $\begin{array}{l}\text { Gastrointestinal system: } \\
\text { Familial polyposis coli } \\
\text { Gardener's syndrome }\end{array}$ & $\begin{array}{l}\text { Intestinal polyps and carcinomas } \\
\text { Intestinal polyps and cancers, osteomas }\end{array}$ & $\begin{array}{l}\mathrm{D} \\
\mathrm{D}\end{array}$ \\
\hline $\begin{array}{l}\text { Vascular System: } \\
\text { Osler-Weber-Rendu syndrome } \\
\text { Ataxia telangiectasia }\end{array}$ & $\begin{array}{l}\text { Angioma } \\
\text { Lymphoma, leukemia, gastric cancer }\end{array}$ & $\begin{array}{l}\mathrm{D} \\
\mathrm{R}\end{array}$ \\
\hline $\begin{array}{l}\text { Urogenetial System: } \\
\text { Wilm's tumor } \\
\text { Stein-Leventhal syndrome }\end{array}$ & Endometrial carcinoma & $\begin{array}{l}\mathrm{D} \text { and } \mathrm{R} \\
\mathrm{D}\end{array}$ \\
\hline $\begin{array}{l}\text { Immunologic Syndromes: } \\
\text { Agammaglobulinemia (Swiss type) } \\
\text { X-linked agammaglobulin- } \\
\text { DiGeorge syndrome }\end{array}$ & $\begin{array}{l}\text { Lymphoma, leukemia } \\
\text { Lymphoma, leukemia } \\
\text { Squamous carcinoma of upper respiratory tract }\end{array}$ & $\begin{array}{c}\mathrm{R} \\
\mathrm{XR} \\
\mathrm{D}\end{array}$ \\
\hline
\end{tabular}

Mode of inheritance: $\mathrm{D}$, autosomal dominant, $\mathrm{R}$, autosomal recessive, $\mathrm{XR}$ 


\section{Invasive}

a. Invasive ductal carcinoma

b. Invasive ductal carcinoma with a predominant intraductal component

c. Invasive lobular carcinoma

d. Mucinous carcinoma

e. Medullary carcinoma

f. Papillary carcinoma

g. Tubular carcinoma

h. Adenoid cycstic carcinoma

i. Secretory (juvenile) carcinoma

j. Apocrine carcinoma

k. Carcinoma with metaplasia

i. Squamous type

ii. Spindle-cell type

iii. Cartilagenous and osseous type

iv. Mixed type

1. Others

\section{Pagets disease of the nipple (4)}

Noninvasive carcinoma : Breast cancer is usually subdivided into noninvasive (in situ) and invasive cancer. In situ carcinoma is characterized by growth within the ducts without penetration of the basement membrane and thus without the ducts involving the stroma. In situ carcinoma is subdivided into ductal carcinoma in situ (DCIS) and lobular carcinoma in situ (LCIS) [4].

DCIS : DCIS is often subdivided into comedo and noncomedo types depending on the presence or absence of comedogenesis, growth pattern (eg. solid, papillary, cribriform) and nuclear grade. The comedo type is characterized by a growth pattern where the cells in the centre of the involved ducts are necrotic and the surrounding viable cells have a high nuclear grade. The central area of necrosis often demonstrates dystrophic calcification [4].

Endocrine ductal carcinoma in situ is a variant growth pattern of ductal carcinoma in situ where the arrangement of cells suggests an endocrine structure. This is a descriptive term which lacks clinical or prognostic significance [4].

LCIS: LCIS is characterized by distention of lobular ducts by a population of uniform, discohesive cells which lack nuclear pleomorphism, nucleoli or mitotic activity. Involvement of one complete lobule in a biopspy is sufficient for the diagnosis, although some consider involvement of most of the lobular ducts sufficient. The lesion is neither palpable nor mammographically evident; therefore, its diagnosis usually relates to its presence adjacent to a clinically or mammographically detectable lesion. Lobular carcinoma in situ is characteristically multicentric and bilateral. It should be considered as an indicator of an increased relative risk for the patient of developing invasive carcinoma [4].

Invasive carcinoma: Invasive carcinoma denotes neoplastic penetration of the basement membrane of a duct containing ductal carcinoma in situ and extension of neoplastic cell aggregates into the mammary stroma [4].

Ductal carcinoma: Ductal carcinoma comprises about $75 \%$ of all invasive breast cancer. The designation ductal carcinoma refers to the belief that this type of carcinoma originates in ducts as opposed to lobules. According to current opinion, ductal as well as lobular invasive carcinoma starts in the terminal duct lobular unit (TDLU). In some classifications, such as the WHO classification, ductal carcinoma has been subdivided into two groups one of which is characterized by reactive fibrosis and is therefore sometimes called cancer with productive fibrosis. This type appears as a spiculated tumor on the mammogram. The other subgroup is less fibrotic and also differs in several other respects. It is more regular in outline and is sometimes referred to as circumscribed carcinoma or ductal carcinoma with a predominant intraductal component [4].

Invasive lobular carcinoma: Invasive lobular carcinoma is characterized by a growth pattern of invasive carcinoma in which the neoplastic cells grow in single cell cords (so called Indian files) and surround ducts in a concentric targetoid arrangement. The cells may have cytoplasmic vacuolation related to intracellular mucin. The neoplasm may be difficult to detect either clinically or mammographically becuase of the frequently meager desmoplastic response and the absence of associated microcalcifications. This growth pattern may be intermixed with ductal forms of invasive carcinoma and may be associated with either lobular carcinoma in situ or ductal carcinoma in situ [4].

Mucinous (colloid) carcinoma: Mucinous (colloid) carcinoma is characterized by abundant extracellular mucin surrounding nests of carcinoma cells. Such carcinomas are typically circumscribed and may have adjacent foci of ductal carcinoma in situ. This neoplastic growth pattern is associated with a relatively favourable prognosis provided that the carcinoma consists almost entirely of the mucinous growth pattern [4].

Medullary carcinoma: Medullary carcinoma is a form of invasive ductal carcinoma characterized by a circumscribed growth pattern, pronounced nuclear polymorphism and mitotic activiy, a syncytial arrangement of the neoplastic cells and a lymphocytic or plasmacellular infiltrate. Ductal carcinoma in situ (DCIS) is often not evident in association with the neoplasm and hormonal receptor studies usually indicate negative reactions for oestrogen and progesterone receptor proteins. Medullary carcinoma, despite its aggressive micrscopical appearance, is associated with a relatively favourable prognosis [4].

Papillary carcinoma: Papillary carcinoma can refer to a noninvasive or invasive carcinoma. The papillary growth pattern results from the presence of carcinoma cells on delicate fibrovascular stalks. In a noninvasive neoplasm the papillary lesion is present within a distended duct and is often attached to more than one site on the duct wall. The neoplastic epithelium on the fibrovascular stalks is multilayered, is often merged with similar epithelium on an adjacent stalk and may have a cribriform appearance. Such non invasive carcinomas may be present in a subareolar duct and be associated with a bloody nipple discharge or in a cystic duct elsewhere in the breast where a mass lesion results [4].

Tubular carcinoma: Tubular carcinoma is a well differentiated form of invasive breast carcinoma. The carcinoma is usually seen to be associated with foci of ductal carcinoma in situ (DCIS) and is characterized microscopically by relatively uniform angulated small 
ducts which invade mammary stroma. The ducts lack a myoepithelial investment, are lined by cells which lack significant nuclear pleomorphism and are surrounded by cellular connective tissue. Tubular carcinomas are always less than $2 \mathrm{~cm}$ in greatest dimension. Lymph nodal metastases are seen in approximately $15 \%$ cases, although fewer than three nodes are usually involved. The neoplasm is associated with an excellent prognosis [4].

Adenoid cystic: A low grade form of invasive carcinoma characterized by growth in the form of mucin-containing cylinders surrounded by both epithelial and myoepithelial cells. This is the only form of invasive carcinoma which typically demonstrates myoepithelial participation [4].

Carcinoma with metaplasia: While foci of metaplastic change are not uncommon in invasive ductal carcinoma, some tumors consist almost entirely of such a growth pattern. Such neoplasms typically are circumscribed and present in postmenopausal women. The metaplasia may be of varying forms, including squamous cells, spindle cells, as well as chondroid, osteoid or even skeletal muscle growth patterns. In some instances only rare foci of recognizable ductal carcinoma in situ or invasive ductal carcinoma are evident, so that diagnostic separation from a primary mammary sarcoma may be difficult. Immuno histochemical studies for high molecular weight cytokeratin may be helpful in resolving the latter situation [4].

\section{Paget's disease}

Paget's disease is the special type of ductal carcinoma which afflicts women in older age. It begins as the typical intraductal cancer that arises from main excretory ducts of the breast and extends intraepithelially to involve the skin of the nipple and areola. Afflicted skin is frequently fissured, ulcerated and oozing. There is surrounding inflammatory hyperemia and edema and often also bacterial infections follow. The histologic hallmark of this tumor is invasion of the epidermis with characteristic tumor cells called Paget's cells. These cells are large and hyperchromaric, surrounded with a lightly stained ring that represents intracellular deposit of mucopolysaccharides. Morphologic picture is similar to the intraductal carcinoma but this type of cancer has better prognosis [5].

\section{Concept of carcinoma}

'Neoplasia' literally means new growth. Neoplastic development has been divided into three distinct stages viz. initiation, promotion and progression. The stage of 'initiation,' which occurs first in the process of neoplastic development, reflects a permanent and irreversible change in the initiated cell, which is presumed to reflect mutational alterations in the cellular genome. The evidence that initiation is the result of a mutational change may be seen from the facts that (1) the efficiency of initiation is proportional to cellular replicative DNA synthesis and (2) for initiation to be 'complete' or 'fixed,' the initiated cell must have undergone at least one and possibly two rounds of cell division in the presence of the agent or with unrepaired DNA damage [6-8].

'Promotion' is an intermediate stage of neoplastic development and its principal characteristic that clearly distinguishes it from the stages of initiation and progression is its operational reversibility. As Boutwell [9], pointed out, the ubiquitous characteristic of promoting agents is their ability to alter gene expression in target cells. Such alteration is, in almost every case studied, dependent on the interaction of a promoting agent with a specific receptor in the target cell. Such interaction is reversible, as is the effect on gene expression. Promoting agensts also have the unique characteristic of stimulating, selectively, an increased rate of cell division in populations of initiated cells.
Furthermore, recent investigations on several promoting agents also have shown their ability to inhibit apoptosis (programmed cell death) in such populations of initiated cells [10].

'Progression' is the final stage of neoplastic development and is characterized primarily by the karyotypic instability of the cell genome and its continuing evolution to more deviant chromosomal patterns [11]. Karyotypic instability and evolution are in turn directly related to the increased growth rate, invasiveness, metastatic capability and biochemical and molecular changes in the malignant cell. Furthermore, just as with the stages of initiation and promotion, spontaneous or fortuitous progression also can be expected to occur during the natural history of neoplastic development, probably resulting from the increased growth rate of cells in the stage of promotion, which in turn, is induced by the presence of the promoting agent whether exogenous or endogenous [11,12]. As Ames and Gold [13] pointed out, mitogenesis itself acts to trigger a variety of clastogenic events spontaneously, events that would probably be much more likely in cells in the stage of promotion than in normal cells.

The development of cancer with most natural etiologic agents is a very long process lasting many years (10 to 40 or more) in which several or many steps occur.

On the basis of the currently accepted view of breast cancer as a multistep process, it is possible that specific abnormalities may be required in the progression from a normal breast epithelial cell to an invasive tumor cell.

\section{Factors involved in breast cancer}

The important risk factors implicated since long, in several epidemiological studies are earlier age at menarche, later age at first full term pregnancy, low parity and later age at menopause.

\section{Aging}

A woman's risk of developing breast cancer increases with age. About $77 \%$ of women with breast cancer are over age 50 at the time of diagnosis. Women younger than 30 years account for only $0.3 \%$ of breast cancer cases. Women in their thirties account for about $3.5 \%$ of cases [14].

\section{Chromosome instability}

The role of genetic changes in neoplasia has been a matter of debate for 100 years. The earliest systematic study of cell division in malignant tumors was made in 1890 by David Hansemann [15]. Later, in 1914, Theodor Boveri [16] first suggested that malignancy might actually result from the disturbance of the normal chromosome balance, essential for normal cell function. This somatic mutation theory of cancer, i.e. the concept that neoplasia originates in a single cell by an acquired genetic change, remains the paradigmatic view of cancer pathogenesis, supported by a wealth of experimental evidence.

Spontaneous chromosome instability has been corelated with cancer predisposition [17]. Most genetic changes in cancers, including the nonrandom type such as the $\mathrm{Ph} 1$ chromosome of the chronic myelogenous leukemias, are acquired in the target cells after the zygotes are formed and the tissues differentiated. Genetic predisposition to cancer, therefore, may be caused by other mechanisms. One of the possibilities is genetic instability, which in some cases is expressed as chromosome instability. Individuals with genetic instability may generate more cells with mutations or chromosomal aberrations than those with more stable genomes. One of these aberrant cells in a target 
tissue may happen to possess a genetic constitution equivalent to the first step of carcinogenesis [18].

\section{Genetic risk factors}

Recent studies have shown that about $10 \%$ of breast cancer cases are directly due to inherited mutations in breast cancer related genes and that most of these result from mutations (changes) of the BRCA1 and BRCA2 genes [19]. In 1990 King's group reported linkage of the disease with a region on the long arm of chromosome 17 (17q 12-21) [20]. In addition to BRCA1 there are two other breast cancer associated genes, BRCA2 and BRCA3 (located on 16q) [21]. In 1994 Wooster and coworkers discovered linkage of a region on the long arm of chromosome 13 with hereditary early onset breast cancer in families that were not linked to $17 \mathrm{q}$. The region (including the gene termed BRCA2) maps to 13 q12-13, proximal to the retinoblastoma gene [22]. About $50 \%$ to $60 \%$ of women with inherited BRCA1 or BRCA2 mutations will develop breast cancer by the age of 70 . Inherited mutations of the p53 tumor suppressor gene can also increase a woman's risk of developing breast cancer. The Li-Fraumeni syndrome, named after the two researchers who described this inherited cancer syndrome, is a rare cause of breast cancer [14].

Breast cancer etiology is multifactorial, involving environmental factors, hormones, genetic susceptibility and genetic changes during progression. The existence of cancer prone families has prompted an intense search for the genes which may predispose individuals to breast and/or ovarian cancers and which may contribute to the far more sporadic forms of the diseases. The two most notorious breast-ovarian cancer susceptibility genes are $B R C A 1$ and $B R C A 2$. Women who inherit a mutated copy of either the BRCA1 or BRCA2 gene have an elevated lifetime risk of breast and ovarian cancer, exceeding $80 \%$ and $30 \%$ by age 70 versus a population risk of $10 \%$ and $1.5 \%$ respectively.

\section{Family history of breast cancer}

Breast cancer risk is higher among women whose close blood relatives have this disease. Blood relatives can be from either the mother's or father's side of the family. Having one first degree relative (mother, sister or daughter) with breast cancer approximately doubles a woman's risk and having two first degree relatives increases her risk 5 fold. Although the exact risk depends on several factors, women with a family history of breast cancer in male family members also have an increased risk of breast cancer [14].

\section{Personal history of breast cancer}

A woman with cancer in one breast has a 3 to 4 fold increased risk of developing a new cancer in the other breast or in another part of the same breast. This is different from a recurrence of the first cancer [14].

\section{Heredity and cancer}

The etiology of human cancers depends upon heredity and environment with environmental agents (solar and other radiation, chemicals, viruses), lifestyle activities (cigarette smoking, alcohol abuse, diet, sexual promiscuity) and occupation contribute significantly to the outcome. The most common ( $90 \%)$ human cancers are not hereditary cancers in the sense of being transmitted by the germline in a Mendelian pattern of inheritance [14].

Nevertheless, molecular genetic evidence supports a new paradigm for cancer, namely, that cancer is a genetic disease in which the accumulation of somatic (or inherited) mutations in genomic
DNA modifies normal cell genes to become cancer genes. Specific chromosomal changes observed at the microscopic or molecular level are known to predispose to or be associated with certain forms of cancer. Most of the physical, chemical or biological (virological) agents that cause neoplastic transformation or cancer are mutagenic.

It is estimated that some $5-10 \%$ of all cancers occurring in the US are either hereditary cancers that are inherited in a Mendelian manner or accompany inherited disease syndromes in which malignant tumors are only one manifestation of a complex disorder (Table 1). These latter syndromes can be inherited by germ line changes as dominant or recessive traits or as autosomal or sex linked traits [14].

\section{Race}

White women are slightly more likely to develop breast cancer than are African-American women. But African Americans are more likely to die of this cancer because they are often diagnosed at an advanced stage when breast cancer is harder to treat and cure. Asian, Hispanic and American Indian women have a lower risk of developing breast cancer [14].

\section{Previous breast biopsy}

Women whose earlier breast biopsies were diagnosed as proliferative breast disease without atypia or usual hyperplasia have a slightly higher risk of breast cancer (1.5 to 2 times greater than other women do). A previous breast biopsy result of atypical hyperplasia increases a woman's breast cancer risk by 4 to 5 times [14].

\section{Previous breast irradiation}

Women who have had chest area radiation therapy as a child or young woman, as treatment for another cancer (such as Hodgkin's disease or non-Hodgkin's lymphoma) are at significantly increased risk for breast cancer [14].

\section{Menstrual periods}

Women who started menstruating at an early age (before age 12) or who went through menopause at a late age (after age 50) have a slightly higher risk of breast cancer [14].

\section{Oral contraceptive use}

It is still not clear what part oral contraceptives (birth control pills) might play in breast cancer risk. A recent analysis using data from most of the large, well-designed, published studies found that women now using oral contraceptives have a slightly greater risk of breast cancer than those women not using them. Women who stopped using oral contraceptives more than 10 years ago do not appear to have any increased breast cancer risk [14].

\section{Not having children}

Women who have had no children or who had their first child after age 30 have a slightly higher breast cancer risk [14].

\section{Hormone replacement therapy}

Most studies suggest that long term use (5 years or more) of hormone replacement therapy (HRT) after menopause may slightly increase the risk of breast cancer. The risk of HRT applies only to current and recent users and a woman's breast cancer risk appears to return to that of the general population within 5 years of stopping HRT. HRT reduces the risk of heart attacks, stroke and bone fractures. The decision to use hormone replacement therapy after menopause should be made by a woman and her doctor after weighing the possible risks 
and benefits. Factors to consider include her other risk factors for heart disease, breast cancer, osteoporosis (thinning and weakening of bones) and the severity of menopausal syndromes [14].

\section{Not breast feeding}

Some studies suggest that breast feeding may slightly lower breast cancer risk, especially if breast feeding is continued for 1.5 to 2 years. Other studies found no impact on breast cancer [14].

\section{Alcohol}

Use of alcohol is clearly linked to increased risk of developing breast cancer. Compared with nondrinkers, women who consume one alcoholic drink a day have a very small increase in risk and those who have 2 to 5 drinks daily, have about 1.5 times the risk of women who drink no alcohol [14].

\section{Obesity and high fat diets}

Obesity (being overweight) is associated with an increased risk of developing breast cancer, especially for women after menopause (which usually occurs at age 50). Although most of a woman's estrogen is produced by her ovaries, fat tissue can change some other hormones into estrogen. Having more fat tissue can increase a woman's estrogen levels and increase her likelihood of developing breast cancer. The connection between weight and breast cancer risk is complex, however. For example, risk appears to be increased for women who gained weight as an adult but not among those who have been overweight since childhood. Also, excess fat in the waist area affects risk more than the same amount of fat in the hips and thighs. Researchers believe that fat cells in various parts of the body have subtle differences in their metabolism that may explain this observation [14].

Studies of fat in the diet as it relates to breast cancer risk have often given conflicting results. Most studies found that breast cancer is less common in countries where the typical diet is low in total fat, low in polyunsaturated fat and low in saturated fat. On the other hand, many studies of women in the United States have not found breast cancer risk to be related to dietary fat intake. Researchers are still not sure how to explain this apparent disagreement. Many scientists note that studies comparing diet and breast cancer risk in different countries are complicated by other differences (such as activity level, intake of other nutrients, genetic factors) that might also alter breast cancer risk [14].

More research is needed to better understand the impact of fat intake (especially the types of fat eaten) and body weight on breast cancer risk. But these factors have been shown to affect the risk of developing several other types of cancer and intake of certain types of fat is clearly related to heart disease risk. The American Cancer Society recommends maintaining a healthy weight and limiting your intake of high fat foods, particularly those from animal sources [14].

\section{Physical inactivity}

Exercise and cancer is a relatively new area of research. Recent studies indicate that strenous exercise in youth might provide lifelong protection against breast cancer and that even moderate physical activity as an adult can lower breast cancer risk. Additional research is underway to confirm these findings [14].

\section{Environmental pollution}

A great deal of research has been reported and more is underway in the field of environmental influences on breast cancer risk. The goal is to determine their possible relationships to breast cancer. Currently, research does not show a clear link between breast cancer risk and exposure to environmental pollutants, such as the pesticide DDE (chemically related to DDT) and PCBs (polychlorinated biphenyls). Although a few studies have suggested certain pollutants increase breast cancer risk, most experts believe that if such a connection exists, it accounts for a very small portion of breast cancer cases [14].

\section{Smoking}

The vast majority of studies on smoking and breast cancer risk have not found any association. Nonetheless, it is clear that smoking negatively affects overall health and increases the risk for many other cancers, as well as heart disease and stroke [14].

\section{Induced abortion}

A large, recent study from Denmark has provided very strong data that induced abortions have no overall effect on the risk of breast cancer. Also, there is no evidence of a direct relationship between breast cancer and spontaneous abortion (miscarriage) in most of the studies that have been published [14].

\section{Breast implants}

Silicone breast implants can cause formation of scar tissue in the breast but several studies have found that they do not increase breast cancer risk. Implants do alter the visualization of breast tissue on standard mammograms but additional $x$ ray pictures called implant displacement views can be used to completely examine the breast tissue [14].

\section{Prophylactic (preventive) mastectomy for women with very high breast cancer risk}

This is a surgical procedure chosen occasionally by a woman who is at very high risk for breast cancer. The purpose is to reduce risk by removing both breasts before breast cancer is diagnosed. The reasons for considering this type of surgery may include one or more of the following risk factors : mutated BRCA genes found by genetic testing, previous cancer in one breast, strong family history (breast cancer in several close relatives) and/or biopsies showing lobular carcinoma in situ (LCIS) [14].

\section{Etiology of breast cancer}

Scientists are making great progress in understanding how certain changes in DNA can cause normal breast cells to become cancerous. DNA is the chemical that carries instructions for nearly everything our cells do. We usually resemble our parents because they are the source of our DNA. However, DNA affects more than our outward appearance [14].

Some genes (parts of DNA) contain instructions for controlling when our cells grow, divide and die. Certain genes that promote cell division are called oncogenes. Others that slow down cell division or cause cells to die at right time are called tumor suppressor genes. It is known that cancers can be caused by DNA mutations (changes) that "turn on" oncogenes and "turn off" tumor suppressor genes. Certain inherited DNA changes can cause a high risk for developing cancer in people who carry these changes and are responsible for the cancers that run in some families [14].

\section{Oncogenes and tumor suppressor genes}

Two classes of genes are implicated in cancer. Some cellular genes (the proto-oncogenes) can be activated by dominant mutations. A proto-oncogene can be converted from a normal cellular gene to an oncogene by a variety of submicroscopic events including point mutations, 
small insertions and deletions and juxtaposition to other chromosome sequences. This last event can be visualized cytogenetically as a translocation or inversion and this observation led to the realization that it was likely that proto-oncogenes might be involved in structural rearrangements [23].

The second type of tumor genes, often referred to as tumor suppressor genes [24], has ben isolated to date only from solid tumors. Like oncogenes, these are also normal cellular genes; however, tumor suppressor genes contribute to oncogenicity through their loss rather than through their activation. Their behavior is recessive and both copies must be inactivated for tumor formation to occur. Again, there are a variety of submicroscopic mutational mechanisms by which this can occur. These are detectable at the DNA level as loss of constitutional heterozygosity in tumor DNA. Loss of the entire gene, the region of the chromosome or even the entire chromosome will also achieve this end and in the case of a tumor suppressor gene, these chromosomal deletions and losses are detected cytogenetically [23].

In general terms, structural rearrangements that consistently juxtapose two different chromosomal regions are thought to contain dominantly acting oncogenic sequences. Deletions or monosomies are believed to be the site of recessive tumor suppressor genes [23].

Most DNA mutations related to cancer, however, occur in single breast cells during a woman's life rather than having been inherited. Acquired mutations of oncogenes and/or tumor suppressor genes may result from radiation or cancer causing chemicals. So far, however, studies have not been able to identify any chemical in the environment or in our diets that is likely to cause these mutations or a subsequent breast cancer. The cause of most acquired mutations remains unknown [14].

Recent advances in understanding the genetic basis of breast cancer have already begun to benefit patients in several ways. Genetic testing can identify some women who have inherited abnormal BRCA1, BRCA 2 or p53 tumor suppressor genes. Genome instability need not arise through germline inactivation of BRCA1 and BRCA2 that function in the maintenance of chromosomal integrity but could arise by spontaneous insult from intrinsic or extrinsic agents. For example, environment, age, diet or other etiological factors represent causative agents in the precipitation of chromosomal damage in sporadic cancers, as could sporadic mutations in genes involved in the maintenance of chromosomal integrity. A more precise understanding of BRCA1/2 function at the mechanistic level will not only provide insight into the pathogenesis of breast cancer but also enhance our knowledge of the molecular basis by which a cell maintains its genomic integrity. We can also expect that novel therapeutic tools designed to specifically interfere with these molecular events will be developed and tested for tumor suppression in a growing company of genetically defined mammary tumor models [24]. These women can then take steps to reduce their risk of developing breast cancers and to monitor changes in their breasts carefully to find any cancer at an earlier, more treatable stage [14].

Most breast cancers have multiple gene mutations. The mutations are not inherited and cannot be passed on but instead develop during a woman's lifetime. It may be useful to identify acquired changes of the HER2 oncogene in some women with breast cancer to aid in making decisions about the best treatment. Tests to identify other acquired changes in oncogenes or tumor suppressor genes (such as p53) may help doctors more accurately predict the prognosis of some women with breast cancer. But with the exception of the HER2 oncogene, these tests have not yet been shown to be useful in making decisions about treatment and are used only for research purposes. A monoclonal antibody therapy called trastuzumab (Herceptin) has been developed that specifically interrupts the growth promoting action of HER2 oncogene [14].

\section{References}

1. Ellen S, Julian B, Audrey DG (1991) Chromosome aberration and cancer. Science 254: 1081-1268.

2. Robbins (1991) Pathologic Basis of Disease. $1^{\text {st }}$ (Edn.) Prism Books Private Limited, Banagalore, pp: $378-382$

3. http://www.kbsplit.hr/rakdojke/index-english.htm

4. http://www.amershamhealth.com/medcyclopaedia/Volume\%20III\%202/BREAST\%20 CANCER\%20HOSTOLOGICAL\%20CLASSIFICATION.asp

5. www.kbsplit.hr/rakdojke/images

6. Warwick GP (1971) Effect of the cell cycle on carcinogenesis. Fed Proc 30: 1760-1765 [Crossref]

7. Borek C, Sachs L (1968) The number of cell generations required to fix the transformed state in X-ray induced transformed. Proc Natl Acad Sci USA 59: 83-85.

8. Mckoemick PJ, Bertram JS (1982) Differential cell cycle phase specificity for neoplastic transformation and mutation to ouabain resistance induced by $\mathrm{N}$-methylN'-nitro-N-nitrosoguanidine in synchronized C3H10T/12 C18 cells. Proc Natl Acad Sci USA 79: 4342-4346.

9. Boutwell RK (1978) Biochemical mechanism of tumor promotion. In: Slaga TJ, Sivak A, Boutwell K, (eds.) Carcinogenesis. Vol. 2.Mechanisms of tumor promotion and carcinogenesis. New York: Raven Press, pp: 49-58.

10. Bursch W, Lauer B, Timmermann-Trosiener I, Barthel G, Schuppler J, et al. (1984) Controlled death (apopotosis) of normal and putative preneoplastic cells in rat liver following withdrawal of tumor promoters. Carcinogenesis 5: 453-458. [Crossref]

11. Pitot HC (1989) Progression: the terminal stage in carcinogenesis. Jpn J Cancer Res 80: 599-607. [Crossref]

12. Pitot HC (1991) Endogenous carcinogenesis: the role of tumor promotion. Proc Soc Exp Biol Med 198: 661-666. [Crossref]

13. Ames BN, Gold LS (1990) Chemical carcinogenesis: too many rodent carcinogens. Proc Natl Acad Sci U S A 87: 7772-7776. [Crossref]

14. von Hansemann D (1890) Ueber asymmetrische Zelltheilung in Epithelkrebsen und deren biologische Bedeutung. Virchows Arch Path Anat 119: 299-326.

15. Boveri T (1914) Zur Frage der Entstehung maligner Tumoren, Gustav Fischer, Jena

16. Teixeira MR, Pandis N, Gerdes AM, Dietrich CU, Bardi G, et al. (1996) Cytogenetic abnormalities in an in situ ductal carcinoma and five prophylactically removed breasts from members of a family with hereditary breast cancer. Breast Cancer Res Treat 38: 177-182.

17. Hopper JL (1997) Genetic susceptibility to breast cancer. Cancer Forum 21: 2-7.

18. Hall JM, Lee MK, Newman B, Morrow JE, Anderson LA, et al. (1990) Linkage of early-onset familial breast cancer to chromosome 17q21. Science 250: 1684-1689. [Crossref]

19. Volgelstein B, Kinzler KW (1994) Has the breast cancer gene been found? Cell 79:1-3 [Crossref]

20. Wooster R, Neuhausen SL, Mangion J, Quirk Y, Ford D, et al. (1994) Localization of a breast cancer susceptibility gene, BRCA2, to chromosome 13q12-13. Science 265: 2088-2090. [Crossref]

21. http://health.yahoo.com/health/cancer_center/acs_crc/breast_cancer/p02.html

22. Knudson AG Jr (1971) Mutation and cancer: statistical study of retinoblastoma. Proc Natl Acad Sci U S A 68: 820-823. [Crossref]

23. Solomon E, Borrow J, Goddard DA (1991) Chromosome Aberrations and Cancer. Science 254: 1154

24. Zheng L, Li S, Boyer TG, Lee WH (2000) Lessons learned from BRCA1 and BRCA2. Oncogene 19: 6159-6175. [Crossref]

Copyright: (C2017 Deshpande T.M. This is an open-access article distributed under the terms of the Creative Commons Attribution License, which permits unrestricted use, distribution, and reproduction in any medium, provided the original author and source are credited. 